\title{
The impact of social insurance on health among middle-aged and older adults in rural China: a longitudinal study using a three-wave nationwide survey
}

\author{
Xinxin $\mathrm{Ma}^{1}$ and Takashi Oshio ${ }^{2^{*}}$ (D)
}

\begin{abstract}
Background: Many studies have examined the impact of social insurance on health, but the results have generally been mixed, presumably because they have not fully addressed potential biases related to the study's crosssectional design. In this study, we conducted a longitudinal analysis to investigate how participation in two social insurance programs in China-the New Rural Social Pension Insurance (NRSPI) and the New Rural Cooperative Medical Scheme (NRCMS) — was associated with health outcomes among middle-aged and older adults in rural China.
\end{abstract}

Methods: Using three-wave longitudinal data from the China Health and Retirement Longitudinal Study conducted in 2011, 2013, and 2015, we estimated the dynamic fixed-effects regression models to examine the association between participation in the NRCMS/NRSPI and six types of health outcomes.

Results: Participation in the NRSPI was positively associated with some health outcomes, but the associations were relatively modest and were observed only for some specific age and household income groups. Participation in NRCMS was not associated with any health outcomes.

Conclusions: The results provide limited evidence of the positive impact of social insurance on health among middle-aged and older adults in rural China. Thus, social insurance programs should be reformed to enhance their positive impact on health.

Keywords: Dynamic fixed-effects regression model, New rural social pension insurance, New rural cooperative medical scheme, Middle-aged and older adults, Rural China

\section{Background}

To maintain the living standard of the elderly and reduce their risk of poverty and poor health in later life, establishing a universal social security system has become an important policy challenge in both developing and developed countries. This is particularly true of

\footnotetext{
* Correspondence: oshio@ier.hit-u.ac.jp

${ }^{2}$ Institute of Economic Research, Hitotsubashi University, 2-1 Naka, Kunitachi-shi, Tokyo 186-8603, Japan

Full list of author information is available at the end of the article
}

China, which is facing the serious problem of an aging population; the proportion of people aged 65 and older is expected to rise rapidly from $10.9 \%$ in 2017 to $26.3 \%$ in 2050 [1].

Correspondingly, an increasing number of studies have examined the impact of social insurance on health in many countries, including China. However, the results have generally been mixed. In terms of the impact of medical insurance on health, studies have obtained inconsistent findings for both developed countries [2-4] 
and developing countries [5-7]. For example, in the case of China, some studies found that medical insurance has a positive impact on health [8-13], while others failed to find any significant impact [14-16]; one study even found a negative impact [17]. Meanwhile, many studies have found public pensions to have a positive impact on health $[7,18,19]$, with one study reporting the positive impact of pensions on health among rural residents in China [18]. However, one study found no significant impact in Korea [20].

In general, social insurance, which includes public pensions and medical insurance, may affect an individual's health in several ways. First, both public pensions and medical insurance may increase the utilization of healthcare services and medical examinations, thus improving people's health [21-23]. Medical insurance can reduce the out-of-pocket (OOP) costs of healthcare and the benefits of public pensions may directly increase household income, which can finance health expenditures. Second, both public pensions and medical insurance can have a positive impact on mental health by reducing uncertainty about future disposable income and health expenditures. Third, medical insurance may lead to problems of moral hazard, which may worsen an individual's health [24]; insured individuals may be more inclined to engage in unhealthy behaviors such as smoking and excessive drinking. Fourth, exposure to the bureaucratic processes used to administer social insurance schemes can also impact health, especially in pensions, disability insurance, and worker compensation schemes [25-28]. Thus, the overall effect of social insurance on health should be evaluated using a large-scale dataset.

In the current study, we attempted to examine the impact of social insurance programs in China-the New Rural Social Pension Insurance (NRSPI) and the New Rural Cooperative Medical Scheme (NRCMS)-on the health of middle-aged and older adults in rural China, using three-wave longitudinal data from the China Health and Retirement Longitudinal Study (CHARLS).

In contrast with other countries, China's social insurance schemes have been fragmented by the population registration system known as Hukou (e.g., rural Hukou and urban Hukou) since the planned economy period $[13,29,30]$. Although a public pension program for urban workers was inaugurated in the 1950 s, the public pension scheme targeting rural Hukou residents was not established until the early 2000s. The NRSPI was formally launched in 2009 as the first pension insurance program to cover rural Hukou residents. Rural residents who are not covered by any other public pension insurance-such as urban employee basic pension insurance (UEBPI) or urban residents' social pension insurance (URSPI)—can join the NRSPI.
Regarding medical insurance, its public scheme for urban workers was established in the 1950s, whereas in rural areas the Cooperative Medical Scheme (CMS), which was managed by the country's communities and unsupported by the central government, was introduced in the 1950s [16]. The proportion of the population enrolled in CMS was as high as $90 \%$ in the late 1970 s. However, with the collapse of the collective economy in the early 1980 s, the coverage rate fell sharply to $5 \%$ in 1985. The NRCMS was introduced in 2003 to replace the CMS and now covers all rural Hukou individuals. The NRCMS is financed by individuals, rural communities, and local and central governments.

This study is expected to make three contributions to the literature on the impact of social insurance on health. First, based on three-wave longitudinal survey data, it addressed statistical issues such as the initial value effect (i.e., the effect of a variable's initial value on its current value) and individual heterogeneity (i.e., an individual's observed and unobserved attributes), and reverse causality. These problems have remained largely unsolved in previous studies, most of which have been cross-sectional. Second, unlike previous studies that concentrated on a specific type of scheme, this study compared both schemes' impacts on health. Third, this study compared the results between different age and household income groups, a feature that previous studies have largely ignored. Notably, we compared the impact of the NRSPI on the health of middle-aged adults who had not started to receive pension benefits, with its impact on those aged 60 or above, unlike previous studies that only considered the latter [18].

\section{Methods}

\section{Study sample}

We used data obtained from the CHARLS, which is a nationwide longitudinal survey conducted by Peking University in representative regions of China in 2011, 2013, and 2015. The survey respondents comprised of individuals aged 45 years or older in the baseline survey. The CHARLS contains rich individual- and householdlevel information, such as a set of indices on health, demographic characteristics, family structure, house ownership, health behavior, and social participation, which were used in this study. The baseline wave included 17,708 individuals in 150 counties/districts and 450 villages/resident communities. The CHARLS is widely used in empirical studies on social insurance or health issues in China [31-34].

This study focused on rural Hukou residents aged 45 years or older in the baseline survey, who committed to at least one of two follow-up surveys. After excluding respondents who were missing key variables used in the statistical analysis, the total number of individuals whose 
data were used in this study was 32,808 (10,245 from 2011, 10,630 from 2013, and 11,933 from 2015). The sample used in the regression differed slightly depending on the model.

\section{Variables}

Key independent variables were binary for participation in the NRSPI and NRCMS. As for health variables, we used six indices of health: (i) self-rated health (SRH), (ii) cognitive function (CF), (iii) mental health prospects (MH1), (iv) mental health at present (MH2), (v) no health issues affecting working capacity (NHP), and (vi) no disease. (i)-(iii) are continuous variables, while (v) and (vi) are binary variables. Regarding SRH and CF, we categorized them as excellent $=5$, very $\operatorname{good}=4, \operatorname{good}=3$, fair $=2$, and poor $=1$, respectively. We constructed the binary variables of SRH and $\mathrm{CF}$ as $1=$ excellent, $0=$ otherwise. As for $\mathrm{MH} 1$, we categorized the answers to the question "How often do you feel hopeful about the future?" into most or all of the time (5-7 days) $=4$, occasionally or a moderate amount of the time (3-4days) = 3 , some or a little of the time (1-2 days) $=2$, and rarely or none of the time $(<$ one day) $=1$. As for $\mathrm{MH} 2$, we categorized the answers to the question "How often have you felt depressed recently?" in a revised order. We constructed a binary variable of $\mathrm{MH} 1$ or $\mathrm{MH} 2$ taking the value 1 when the value of $\mathrm{MH} 1$ or $\mathrm{MH} 2$ is equal to 4, and 0 otherwise. MH1 was part of the original questionnaire in the CHARLS, and was used for the first time in this study.

Regarding NHP, we constructed a binary variable for it by allocating 1 to the answer "no health problems at work" and 0 otherwise. We also constructed a binary variable of no disease by allocating 1 to those who answered that they had no disease diagnosed by doctors and 0 otherwise.

We considered the following as covariates, all of which are likely to have affected the association between social insurance and health and available from the CHARLS: (1) demographic factors including age, gender, and educational attainment (junior high school and lower, senior high school, and college or higher); (2) family factors including having a spouse or not, having living parents or not, number of family members, and living arrangement with children (residing together or apart); (3) house ownership; (4) health behavior (smoking and drinking); (5) social participation (participating in at least one of its seven types); (6) regions (east, central, west, and northeast), and (7) survey years (2011, 2013, and 2015). We used house ownership as a proxy for household income because using household income would substantially reduce the sample size due to missing variables. Housing assets share the largest portion (59.1\%) of total household assets according to the 2013 China Household
Income Project Survey, and it is positively correlated with household income [35].

The NRSPI benefit consists of two components: (i) the basic pension benefit fully funded by government subsidies, and (ii) the benefit corresponding to an individual's contributions accumulated in a personal account. According to the CHARLS, the average NRSPI benefit in 2011 was $965 \mathrm{CNY}$ per year, which was equivalent to $10.5 \%$ of per capita household income. Meanwhile, the NRCMS is a reimbursement system; its participants must first pay the total healthcare fee by themselves, and then seek reimbursement after submitting claims to their local governments. The NRCMS mostly covers inpatient and serious diseases, while most outpatients are excluded. The OOP rate is around $30 \%$, which varies depending on the type of disease and region.

\section{Analytic strategy}

As the benchmark, we considered the regression model to explain the health variable by participation in the NRSPI and NRCMS along with a set of covariates, X:

$$
\begin{aligned}
H_{i}= & a+\beta N R S P I_{i}+\gamma N R C M S_{i}+\sum_{n} \delta_{n} X_{n i} \\
& +\varepsilon_{i},
\end{aligned}
$$

where $i$ denotes the individual and $\varepsilon$ is an error term. If $\varepsilon$ includes an individual-specific, time-invariant factor, heterogeneity problems may occur when these factors are not controlled for. To address this problem, we used the fixed-effects (FE) or random-effects (RE) model. We employed the $F$ test, the Breusch and Pagan Lagrange multiplier test, and the Hausman specification test to compare the appropriateness of pooled ordinary least squares, FE, and RE models. As the results of these tests indicated that the FE model was the most appropriate, we employed it in this study.

We further considered an initial value problem [3638]: health at time $t$ might be affected by health at time $t-1$. To address this problem, we considered a dynamic FE model, which includes health at time $t-1$ as an explanatory variable. We further replaced all other explanatory variables at time $t$ with those at time $t-1$ to mitigate the reverse causality problem by allowing a one-wave (that is, two-year) lag from the explanatory variables to health $[39,40]$. Overall, we estimated dynamic FE models with lagged explanatory variables using balanced panel data:

$$
\begin{aligned}
H_{i t}= & a+\rho H_{i t-1}+\beta N R S P I_{i t-1} \\
& +\gamma N R C M S_{i t-1}+\sum_{n} \delta_{n} X_{n i t-1}+u_{i t},
\end{aligned}
$$

where $t$ and $t-1$ denote a combination of survey years (2013 and 2011) or (2015 and 2013), and $u$ is an error term. In the actual regression analysis, we estimated 
logistic regression models using a set of binary variables of health indices, rather than linear models. We estimated the regression models not only for the entire sample, but also for each age group (aged 45-59, 60-64, and 65 or above) and household income group (low, middle, and high) to examine heterogeneity.

\section{Results}

\section{Descriptive analysis}

Table 1 summarizes the key features of the study sample used in the statistical analysis. Figure 1 summarizes the participation rates of the NRSPI and NRCMS from 2011 to 2015. The participation rates for the NRSPI rose from $35.7 \%$ in 2011 to $69.4 \%$ in 2013 and $67.5 \%$ in 2015, indicating that the Chinese government succeeded in raising participation in public pensions for rural areas after introducing them in 2009. By comparison, the enrollment percentage in the NRCMS, which was introduced in 2003, remained high during the study period at approximately $90 \%$. The proportion of participants in both the NRSPI and NRCMS rose from 33.5\% in 2011 to $65.4 \%$ in 2013 and $61.6 \%$ in 2015 , largely reflecting the increase in participation rates for the NRSPI.

Table 2 presents the unadjusted association between participation in social insurance programs and health outcomes, comparing health outcomes between participants and non-participants in the NRSPI and NRCMS using the entire sample. NRSPI participation was negatively associated with $\mathrm{CF}, \mathrm{MH} 2$, and no disease, and positively associated with MH1. Meanwhile, participation in the NRCMS was negatively associated with all health outcomes except for MH2. It should be noted, however, that the comparisons in this table did not control for covariates and were not adjusted for potential biases related to cross-sectional comparisons. The results for each survey year (see Additional file 1) showed almost the same pattern as seen in the entire sample reported in Table 2.

\section{Regression analysis}

The results of the regression models are summarized in Table 3, which reports the odds ratios (ORs) of reporting better health status, along with $95 \%$ confidence intervals (CIs), in response to participation in the NRSPI and NRCMS. Unlike the results based on the cross-sectional data reported in Table 2, there was no negative association with any health outcome.

Specifically, the table shows that participation in the NRSPI had positive and significant $(p<0.05)$ associations with CF (OR: 1.30, 95\% CI: 1.10,1.57) and no disease (OR: 1.01, 95\% CI: 1.00,1.03), while it had less significant but positive associations $(p<0.1)$ with SRH (OR: 1.06 , 95\% CI: 0.97,1.18) and MH2 (OR: 1.07, 95\% CI: 0.99, 1.17). The positive association between participation in

Table 1 Key features of the study sample

\begin{tabular}{|c|c|c|c|c|c|}
\hline & $N$ & $\%$ & & $N$ & $\%$ \\
\hline Demographic factors & & & Health behavior & & \\
\hline Gender & & & Smoking & & \\
\hline Men & 15,678 & $(46.9)$ & No smoking & 10,564 & $(31.6)$ \\
\hline Women & 17,751 & $(53.1)$ & Smoking in the past & 14,207 & $(42.5)$ \\
\hline \multirow[t]{2}{*}{ Age (years) } & M & 59.3 & Smoking currently & 8658 & $(25.9)$ \\
\hline & SD & $(9.6)$ & Drinking & & \\
\hline Educational attainment & & & No drinking & 25,139 & $(75.2)$ \\
\hline Junior high school or lower & 31,423 & $(94.0)$ & Drinking per week & 6686 & $(20.0)$ \\
\hline Senior high school & 1791 & $(5.7)$ & Drinking per month & 1604 & $(4.8)$ \\
\hline College or higher & 215 & $(0.3)$ & Social participation & 15,277 & $(45.7)$ \\
\hline Family factors & & & Regions & & \\
\hline Having a spouse & 29,016 & $(86.8)$ & East & 6285 & $(18.8)$ \\
\hline Having living parents & 4413 & $(16.9)$ & Central & 6920 & $(20.7)$ \\
\hline Living arrangement with children & & & West & 19,355 & $(57.9)$ \\
\hline Living together & 18,597 & $(57.0)$ & Northeast & 869 & $(2.6)$ \\
\hline Living apart & 14,211 & $(43.0)$ & Survey years & & \\
\hline \multirow[t]{2}{*}{ Number of family members } & M & 3.47 & 2011 & 10,530 & $(31.5)$ \\
\hline & SD & $(1.7)$ & 2013 & 10,864 & $(32.5)$ \\
\hline House ownership & 20,325 & $(60.8)$ & 2015 & 12,035 & $(36.0)$ \\
\hline N & & & & 33,429 & \\
\hline
\end{tabular}

The age and number of family members are shown by mean values 


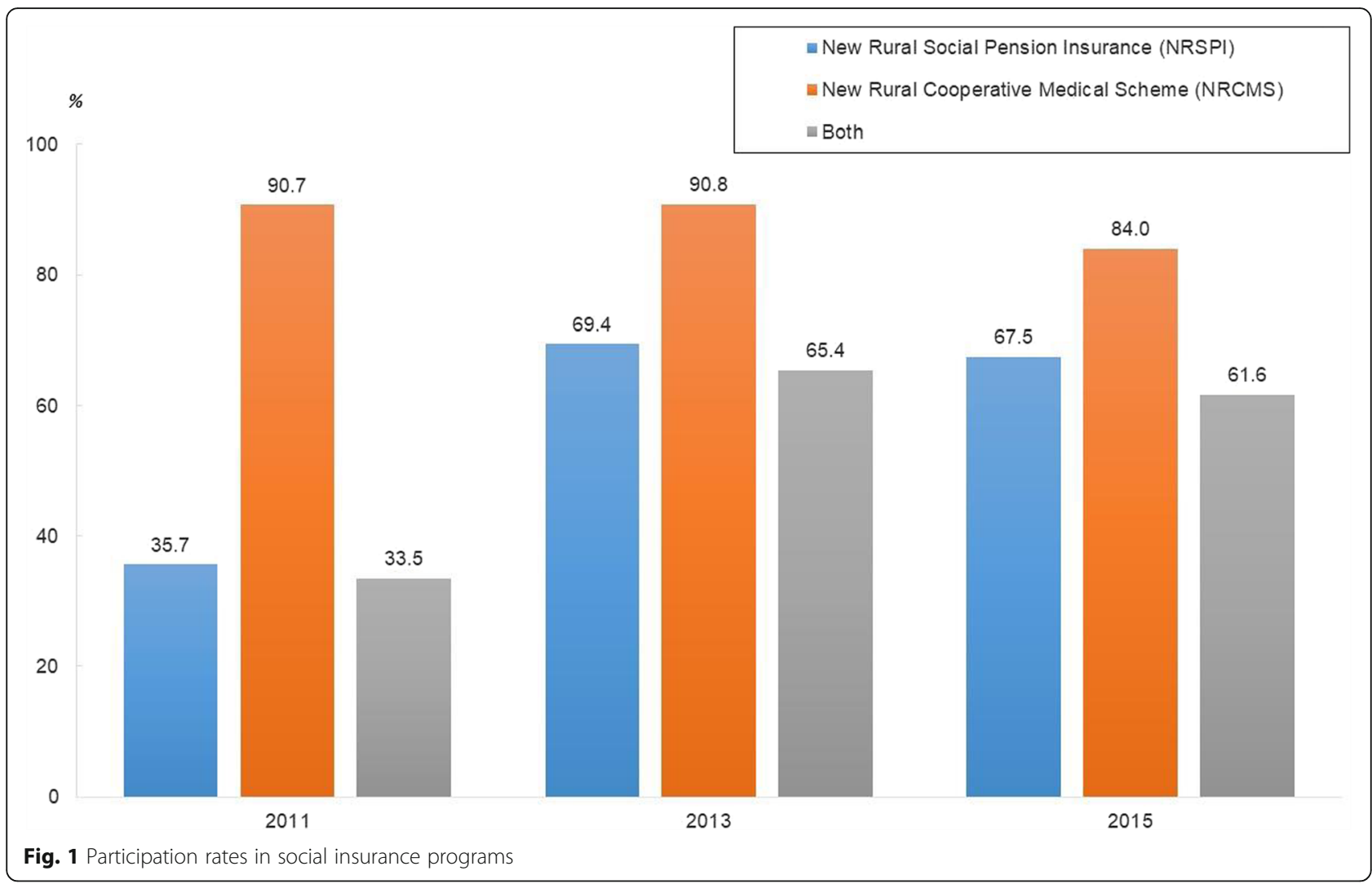

the NRCMS and health was more limited, as it only had a modest association with MH2 (OR: 1.07, 95\% CI: 0.97,1.08).

Tables 4 and 5 summarize the results obtained from separate estimations by age and household income, respectively. Table 4 indicates that participation in the NRSPI had modestly positive associations with SRH, CF, and MH2 $(p<0.1)$ among those aged $45-59$, while the results were mixed among older age groups; participation in the NRSPI was negatively associated with NH1

Table 2 Unadjusted association between participation in social insurance programs and health outcomes ${ }^{\mathrm{a}}$ : total sample in $2011-2015$

\begin{tabular}{|c|c|c|c|c|c|c|c|c|c|}
\hline \multirow[t]{2}{*}{ Proportion (\%) } & \multirow{2}{*}{$\begin{array}{l}\text { Participants } \\
\text { (a) }\end{array}$} & \multirow{2}{*}{$\begin{array}{l}\text { Non-participants } \\
\text { (b) }\end{array}$} & \multicolumn{2}{|c|}{ Difference } & \multicolumn{2}{|c|}{ Participants } & \multicolumn{2}{|c|}{ Non-participants } & \multirow{2}{*}{$\begin{array}{l}\text { Total } \\
N\end{array}$} \\
\hline & & & (a) - (b) & $t$-test & $N$ & $\%$ & $N$ & $\%$ & \\
\hline \multicolumn{10}{|l|}{ New Rural Social Pension Insurance (NRSPI) } \\
\hline Self-rated health (SRH: 1-5) & 2.13 & 2.12 & 0.01 & 0.440 & 22,124 & $(60.1)$ & 14,669 & $(39.9)$ & 36,793 \\
\hline Cognitive function (CF: 1-5) & 1.83 & 1.86 & -0.03 & $p<0.001$ & 22,601 & $(58.4)$ & 16,118 & $(41.6)$ & 38,719 \\
\hline Mental health in prospect (MH1: 1-4) & 3.12 & 3.07 & 0.05 & $p<0.001$ & 22,274 & $(58.4)$ & 15,869 & $(41.6)$ & 38,143 \\
\hline Mental health at present $(\mathrm{MH} 2: 1-4)$ & 2.52 & 2.61 & -0.09 & $p<0.001$ & 21,794 & $(58.4)$ & 15,493 & $(41.6)$ & 37,287 \\
\hline No health problem for working (NHP: 0-1) & 0.66 & 0.67 & -0.01 & 0.142 & 15,480 & $(58.9)$ & 10,787 & $(41.1)$ & 26,267 \\
\hline No disease (0-1) & 0.27 & 0.30 & -0.03 & $p<0.001$ & 24,434 & $(58.0)$ & 17,679 & $(42.0)$ & 42,113 \\
\hline \multicolumn{10}{|l|}{ New Rural Cooperative Medical Scheme (NRCMS) } \\
\hline Self-rated health (SRH: 1-5) & 2.12 & 2.22 & -0.11 & $p<0.001$ & 32,516 & $(88.3)$ & 4304 & $(11.7)$ & 36,820 \\
\hline Cognitive function (CF: 1-5) & 1.84 & 1.89 & -0.06 & $p<0.001$ & 34,334 & $(88.6)$ & 4405 & $(11.4)$ & 38,739 \\
\hline Mental health in prospect (MH1: 1-4) & 3.09 & 3.15 & -0.06 & $p<0.001$ & 33,843 & $(88.7)$ & 4317 & $(11.3)$ & 38,160 \\
\hline Mental health at present (MH2: 1-4) & 2.56 & 2.54 & 0.02 & 0.432 & 33,114 & $(88.8)$ & 4190 & $(11.2)$ & 37,304 \\
\hline No health problem for working (NHP: 0-1) & 0.66 & 0.70 & -0.04 & $p<0.001$ & 23,736 & $(90.3)$ & 2542 & $(9.7)$ & 26,278 \\
\hline No disease (0-1) & 0.28 & 0.32 & -0.04 & $p<0.001$ & 37,263 & $(88.4)$ & 4912 & $(11.6)$ & 42,175 \\
\hline
\end{tabular}

${ }^{\mathrm{a}}$ The higher the score, the better the health outcomes 
Table 3 Estimated associations between participation in social insurance and health outcomes ${ }^{a}$

\begin{tabular}{lccc}
\hline & OR & $95 \%$ Cl & N \\
\hline New Rural Social Pension Insurance (NRSPI) & & & \\
Self-rated health (SRH) & $1.06 \mathbf{t}$ & $(0.97,1.18)$ & 18,358 \\
Cognitive function (CF) & $1.30^{* *}$ & $(1.10,1.57)$ & 21,714 \\
Mental health prospects (MH1) & 0.94 & $(0.92,1.12)$ & 20,002 \\
Mental health at present (MH2) & $1.07 \mathbf{t}$ & $(0.99,1.17)$ & 10,190 \\
No health problem for working (NHP) & 0.95 & $(0.85,1.06)$ & 11,878 \\
No disease & $1.01^{*}$ & $(1.00,1.03)$ & 21,776 \\
New Rural Cooperative Medical Scheme (NRCMS) & & \\
Self-rated health (SRH) & 1.01 & $(0.98,1.00)$ & 18,358 \\
Cognitive function (CF) & 0.96 & $(0.77,1.20)$ & 21,714 \\
Mental health prospects (MH1) & 1.02 & $(0.91,1.12)$ & 20,002 \\
Mental health at present (MH2) & $1.07 \boldsymbol{(}$ & $(0.97,1.08)$ & 10,190 \\
No health problem for working (NHP) & 0.79 & $(0.65,0.93)$ & 11,878 \\
No disease & 0.95 & $(0.78,1.16)$ & 21,776 \\
\hline
\end{tabular}

${ }^{a}$ Obtained from the dynamic fixed-effects ordered logistic or logistic models with lagged explanatory variables (controlled for covariates)

${ }^{*} p<0.05,{ }^{* *} p<0.05,{ }^{\dagger} p<0.1$

and NHP $(p<0.05)$ among those aged 65 or above. In general, the results for the NRCMS were more mixed, in such a way that no clear pattern emerged.

Table 5 compares the association between participation in the NRSPI/NRCMS and health by household income group. The most noticeable finding was that participation in the NRSPI was positively associated with $\mathrm{SRH}, \mathrm{CF}$, and no disease $(p<0.05)$, and to a lesser extent MH2 $(p<0.1)$ among the low-income group. Excluding these combinations, neither the NRSPI nor NRCMS were associated with any health outcome.

\section{Discussion}

We examined how two social insurance programs, the NRSPI and NRCMS, were associated with health among middle-aged and older adults in rural China. Our longitudinal regression analysis, based on dynamic FE models with lagged explanatory variables, indicated that participation in the NRSPI had positive associations with some health outcomes, but that the associations were relatively modest and were observed only for some specific age and household income groups. Meanwhile, participation in the NRCMS was not associated with any health outcome. These results are generally in line with the mixed results from previous studies in China [8-17], which did not fully control for statistical biases. Regarding the association between the NRSPI and health, our results contrasted with those of Cheng et al. [18], who reported more positive results using the CHARLS data. However, there are three differences between their study and ours. First, we used three-wave longitudinal survey data from 2011 to 2015, whereas they only used two-wave (2008/ 2009 vs. 2010/2011) data. Second, we employed dynamic FE models with lagged explanatory variables, whereas they employed the usual FE and FE models with instrumental variables. Third, we included individuals aged 45-59 in the sample, whereas they focused solely on those aged 60 and above. As for the association between medical insurance and health in China, most previous studies reported that the NRCMS increased the probability of healthcare utilization and improved health $[12$,

Table 4 Estimated associations between participation in social insurance and health outcomes by age group ${ }^{a}$

\begin{tabular}{|c|c|c|c|c|c|c|}
\hline & \multicolumn{2}{|c|}{ Aged 45-59 } & \multicolumn{2}{|c|}{ Aged 60-64 } & \multicolumn{2}{|c|}{ Aged 65 or above } \\
\hline & $\overline{O R}$ & $95 \% \mathrm{Cl}$ & $\overline{\mathrm{OR}}$ & $95 \% \mathrm{Cl}$ & $\overline{O R}$ & $95 \% \mathrm{Cl}$ \\
\hline \multicolumn{7}{|l|}{ New Rural Social Pension Insurance (NRSPI) } \\
\hline Self-rated health (SRH) & $1.12^{+}$ & $(0.98,1.28)$ & 1.19 & $(0.95,1.49)$ & 0.92 & $(0.77,1.10)$ \\
\hline Cognitive function (CF) & $1.24^{+}$ & $(0.99,1.54)$ & $1.98^{* *}$ & $(1.33,2.94)$ & 1.12 & $(0.79,1.60)$ \\
\hline Mental health prospects ( $\mathrm{MH} 1)$ & 1.00 & $(0.89,1.11)$ & 0.95 & $(0.79,1.13)$ & $0.85^{*}$ & $(0.75,0.98)$ \\
\hline Mental health at present $(\mathrm{MH} 2)$ & $1.11^{\dagger}$ & $(0.98,1.24)$ & 1.07 & $(0.88,1.29)$ & 1.05 & $(0.88,1.26)$ \\
\hline No health problem for working (NHP) & 0.99 & $(0.86,1.14)$ & 1.08 & $(0.84,1.38)$ & $0.77^{*}$ & $(0.59,1.00)$ \\
\hline No disease & 1.12 & $(0.92,1.36)$ & $0.75^{\dagger}$ & $(0.54,1.05)$ & 1.09 & $(0.81,1.48)$ \\
\hline \multicolumn{7}{|c|}{ New Rural Cooperative Medical Scheme (NRCMS) } \\
\hline Self-rated health (SRH) & 0.88 & $(0.73,1.28)$ & 0.90 & $(0.66,1.22)$ & 0.89 & $(0.71,1.10)$ \\
\hline Cognitive function (CF) & 0.90 & $(0.66,1.21)$ & $0.66^{*}$ & $(0.41,1.08)$ & 1.37 & $(0.87,2.17)$ \\
\hline Mental health in prospect (MH1) & 1.00 & $(0.86,1.17)$ & 1.15 & $(0.90,1.46)$ & 0.99 & $(0.82,1.18)$ \\
\hline Mental health at present $(\mathrm{MH} 2)$ & 0.97 & $(0.82,1.21)$ & 0.88 & $(0.68,1.13)$ & 1.07 & $(0.86,1.33)$ \\
\hline No health problem for working (NHP) & $0.66^{* * *}$ & $(0.54,0.82)$ & 1.09 & $(0.76,1.56)$ & 1.00 & $(0.70,1.43)$ \\
\hline No disease & 0.85 & $(0.65,1.12)$ & $1.58^{*}$ & $(1.00,2.49)$ & 0.83 & $(0.56,1.21)$ \\
\hline
\end{tabular}

abtained from the dynamic fixed-effects ordered logistic or logistic models with lagged explanatory variables (controlled for covariates)

${ }^{* * *} p<0.001,{ }^{* *} p<0.01,{ }^{*} p<0.05,{ }^{\dagger} p<0.1$ 
Table 5 Estimated associations between participation in social insurance and health outcomes by household income group ${ }^{a}$

\begin{tabular}{|c|c|c|c|c|c|c|}
\hline & \multicolumn{2}{|l|}{ Low } & \multicolumn{2}{|c|}{ Middle } & \multicolumn{2}{|l|}{ High } \\
\hline & OR & $95 \% \mathrm{Cl}$ & OR & $95 \% \mathrm{Cl}$ & OR & $95 \% \mathrm{Cl}$ \\
\hline \multicolumn{7}{|l|}{ New Rural Social Pension Insurance (NRSPI) } \\
\hline Self-rated health (SRH) & $1.28^{*}$ & $(1.02,1.59)$ & 0.99 & $(0.79,1.25)$ & 1.16 & $(0.94,1.45)$ \\
\hline Cognitive function (CF) & $2.04^{* * *}$ & $(1.29,3.00)$ & 0.98 & $(0.64,1.51$ & 1.30 & $(0.91,1.88)$ \\
\hline Mental health prospects $(\mathrm{MH} 1)$ & 1.00 & $(0.84,1.20)$ & 0.87 & $(0.72,1.04)$ & 0.86 & $(0.72,1.04)$ \\
\hline Mental health at present $(\mathrm{MH} 2)$ & $1.18^{\dagger}$ & $(0.97,1.43)$ & 0.90 & $(0.75,1.10)$ & 1.06 & $(0.88,1.28)$ \\
\hline No health problem for working (NHP) & 1.07 & $(0.76,1.52)$ & 0.98 & $(0.77,1.24)$ & 0.94 & $(0.74,1.20)$ \\
\hline Non-disease & $1.28^{*}$ & $(1.02,1.59)$ & 0.96 & $(0.67,1.39)$ & $1.36^{\dagger}$ & $(0.96,1.92)$ \\
\hline \multicolumn{7}{|c|}{ New Rural Cooperative Medical Scheme (NRCMS) } \\
\hline Self-rated health (SRH) & 0.88 & $(0.64,1.20)$ & 0.86 & $(0.63,1.17)$ & 0.90 & $(0.70,1.17)$ \\
\hline Cognitive function (CF) & 1.05 & $(0.60,1.83)$ & 0.87 & $(0.50,1.50)$ & 0.82 & $(0.54,1.24)$ \\
\hline Mental health in prospect $(\mathrm{MH} 1)$ & $1.27^{\dagger}$ & $(0.96,1.65)$ & 0.96 & $(0.75,1.21)$ & 0.87 & $(0.70,1.09)$ \\
\hline Mental health at present $(\mathrm{MH} 2)$ & 1.03 & $(0.77,1.36)$ & 1.01 & $(0.78,1.32)$ & 0.80 & $(0.64,1.00)$ \\
\hline No health problem for working (NHP) & 1.29 & $(0.80,2.08)$ & 0.91 & $(0.66,1.27)$ & 0.83 & $(0.60,1.13)$ \\
\hline Non-disease & 0.88 & $(0.64,1.20)$ & 0.80 & $(0.46,1.38)$ & 1.24 & $(0.83,1.86)$ \\
\hline
\end{tabular}

abtained from the dynamic fixed-effects ordered logistic or logistic models with lagged explanatory variables (controlled for covariates)

${ }^{* * *} p<0.001,{ }^{*} p<0.05,{ }^{+} p<0.1$

21, 30, 41]. These previous studies used data from earlier periods (such as 2000-2008) than ours (2011-2013), suggesting that the impact of the NRCMS on health should be analyzed from both short-term and long-term perspectives.

Our estimation results indicated a positive, albeit modest, impact of the NRSPI on health among rural Hukou residents, particularly among those aged 45-60 and from low-income groups. These results suggest that the NRSPI may help have a positive, albeit modest, and indirect effect on people's health in rural areas by reducing uncertainty about income after retirement, especially among low-income groups.

Meanwhile, no positive impact of the NRSPI on health was consistently observed among those aged 60 and older. The adaptation hypothesis can explain why individuals are more likely to take pension benefits for granted when they continue to receive them over a period of time. The results were also likely attributable to low levels of NRSPI benefits, which were below the poverty line in rural areas. According to the CHARLS, the individual average NRSPI pension benefit in 2011 and 2013 was 965 CNY per year, compared to the $2300 \mathrm{CNY}$ per year standard poverty line in rural areas since 2011 [42].

We also found that the NRCMS had no impact on most health outcomes, pointing to limitations in this program compared to the public medical insurance covering urban workers, the Urban Employee Basic Medical Insurance (UEBMI). Although the percentage of OOP for healthcare expenditure is regulated to be $30 \%$ in both the NRCMS and UEBMI, most outpatients are excluded from the NRCMS, and fewer types of fatal diseases are covered by it. Moreover, the reinvestment system in the NRCMS may make low-income individuals more inclined to avoid using healthcare services. These factors seem to explain the limited impact of the NRCMS, which was expected to improve the health outcomes of rural Hukou residents.

Based on the results of this study, the Chinese government should increase NRSPI benefits to support income conditions for rural Hukou residents, particularly those with low incomes. The government should also reform the NRCMS to reduce the payment of healthcare fees by rural Hukou residents and cover outpatients, as well as more types of diseases.

\section{Conclusions}

We conclude that the NRSPI is positively associated with some health outcomes, but that the associations are relatively modest and observed only in some specific age and household income groups. Participation in the NRCMS has no association with any health outcomes. These results provide limited evidence of the positive impact of social insurance on health among middle-aged and older adults in rural China.

This study has several limitations. First, although we used dynamic FE models with lagged explanatory variables, we could not identify the causation from social insurance to health, which should be investigated in a more in-depth analysis. Second, because we focused on individuals aged 45 or older due to data limitations, future studies should expand the analysis to include younger individuals. Third, the question of why the 
association with social insurance was observed for selected types of health outcomes remains unanswered.

Despite these limitations, we believe that the current study, which took full advantage of longitudinal data, provides new insights for understanding the association between social insurance and health. We also expect the Chinese experience of reforming social insurance policy for rural Hukou residents to provide valuable lessons for developing countries that are also looking to establish or reform their own social insurance schemes.

\section{Supplementary Information}

The online version contains supplementary material available at https://doi. org/10.1186/s12889-020-09945-2

\section{Additional file 1.}

\section{Abbreviations}

CF: Cognitive function; CHARLS: China Health and Retirement Longitudinal Study; Cl: Confidence interval; CMS: Cooperative Medical Scheme; FE: Fixedeffects; $\mathrm{MH1}$ : Mental health prospects; $\mathrm{MH} 2$ : Mental health at present; NHP: No health problem for working; NRCMS: New Rural Cooperative Medical Scheme; NRSPI: New Rural Social Pension Insurance; OOP: Out-ofpocket; OR: Odds ratio; RE: Random-effects; SRH: Self-rated health; UEBMI: Urban Employee Basic Medical Insurance

\section{Acknowledgments}

Not applicable.

\section{Authors' contributions}

$\mathrm{XM}$ and TO organized this research project and conceptualized and designed the study. XM conducted data collection and performed a formal analysis. XM and TO prepared the initial manuscript, and reviewed and edited the manuscript. XM and TO acquired the funds. All authors have read and approved the final manuscript.

\section{Funding}

This research was financially supported by the Japan Society for the Promotion of Science (JSPS KAKENHI, Grant Numbers 20H01512 and 20 K01722). The funding body had no role in the design of the study, the collection, analysis, and interpretation of the data, and in writing the manuscript.

\section{Availability of data and materials}

The dataset that was used in this study, the China Health and Retirement Longitudinal Study (CHARLS), is publicly available (http:// charls.pku.edu.cn/en).

\section{Ethics approval and consent to participate}

The dataset that was used in this study, the China Health and Retirement Longitudinal Study (CHARLS), is publicly available (http://charls.pku.edu.cn/ en), and its study protocol was approved by the Ethical Review Committee of Peking University, China. Hence, ethical approval was not required for this study. Survey data was obtained from Peking University with its official permission. Therefore, the current study did not require further ethical approval and the need for written consent was waived by the committee.

\section{Consent for publication}

Not applicable.

\section{Competing interests}

The authors declare no competing interests.

\section{Author details}

${ }^{1}$ Faculty of Social Sciences, University of Toyama, 3190 Gofuku, Toyama 930-8555, Japan. ${ }^{2}$ Institute of Economic Research, Hitotsubashi University, 2-1 Naka, Kunitachi-shi, Tokyo 186-8603, Japan.

Received: 1 September 2020 Accepted: 19 November 2020

Published online: 01 December 2020

\section{References}

1. OECD. Pensions at a glance 2019. Paris: OECD; 2019.

2. Courtin E, Kim S, Song S, Yu W, Muennig P. Can social policies improve health? A systematic review and meta-analysis of 38 randomized trials. Milbank O. 2020:98(2):297-371.

3. Finkelstein A, McKnight R. What did Medicare do? The initial impact of Medicare on mortality and out of pocket medical spending. J Public Econ. 2008;92(7):1644-68.

4. Jensen R, Richer K. The health implications of social security failure: evidence from the Russian pension crisis. J Public Econ. 2004;88(1):209-36.

5. Case A. Does money protect health? Evidence from South Africa pensions In: Wise D, editor. Perspectives on the economics of ageing. Chicago: University of Chicago Press; 2004. p. 287-312.

6. Card D, Dobkin C, Maestas N. Does Medicare save lives? Q J Econ. 2009; 124(2):597-636.

7. Schatz E, Gómez-Olivé X, Ralston M, Menken J, Tollman S. The impact of pensions on health and wellbeing in rural South Africa: does gender matter? Soc Sci Med. 2012;75(10):1864-73.

8. Cheng L, Liu H, Zhang Y, Shen $K$, Zeng $Y$. The impact of health insurance on health outcomes and spending of the elderly: evidence from China's new cooperative medical scheme. Health Econ. 2015;24(6):672-91.

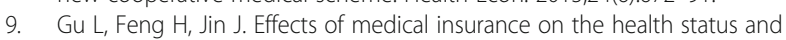
life satisfaction of the elderly. Iran J Public Health. 2017;46(9):1193-203.

10. Huang F, Gan L. Excessive demand or effective demand? Empirical analysis of urban elderly health and medical insurance. J Econ Res. 2010;40:105-19 (in Chinese).

11. Huang F, Wu C. Impact of China's medical insurance on urban elderly mortality rate. Nankai Econ Res. 2009;42:126-37 (in Chinese).

12. Jiang $K$, You D, Li Z, Wei W, Mainstone M. Effects of rural medical insurance on chronically ill patients' choice of the same hospital again in rural northern China. Int J Environ Res Public Health. 2018;15(4):731.

13. Qin X, Pan J, Liu GG. Does participating in health insurance benefit the migrant workers in China? An empirical investigation. China Econ Rev. 2014; 30:263-78.

14. Bai CE, Wu B. Health insurance and consumption: evidence from China's new cooperative medical scheme. J Comp Econ. 2014;42(2):450-69.

15. Chen $Y$, Jin GZ. Does health insurance coverage lead to better health and educational outcomes? Evidence from rural China. J Health Econ. 2012;31(1):1-14

16. Lei $X$, Lin $W$. The new cooperative medical scheme in rural China: does more coverage mean more service and better health? Health Econ. 2009; 18(Suppl 2):S25-46.

17. Luo C. Study on the health differences of urban residents and medical expenditure behavior. Stud Finance Econ. 2008;34:63-75 (in Chinese).

18. Cheng LG, Liu H, Zhang Y, Zhao Z. The health implications of social pensions: evidence from China's new rural pension scheme. J Comp Econ. 2018;46(1):53-77.

19. Galiani S, Gertler P, Bando R. Non-contributory pensions. Labour Econ. 2016; 38:47-58.

20. Pak TY. Social protection for happiness? The impact of social pension reform on subjective well-being of the Korean elderly. J Policy Model. 2019; 42(2):349-66.

21. Pan J, Lei $X$, Liu GG. Health insurance and health status: exploring the causal effect from a policy intervention. Health Econ. 2016;25(11):1389-402.

22. Cuong VN. The impact of voluntary health insurance on health care utilization and out of pocket payment: new evidence for Vietnam. Health Econ. 2012;21(8):946-66.

23. Wagstaff A, Lindelow M, Gao J, Xu L, Qian JC. Extending health insurance to the rural population: an evaluation of China' cooperative medical scheme. J Health Econ. 2009;28(1):1-19.

24. Arrow KJ. The economics of agency. In: John WP, Richard JZ, editors. Principals \& agents: the structure of business. Boston: Harvard Business School Press; 1984. p. 37-51. 
25. Bartys S, Frederiksen P, Bendix T, Burton K. System influences on work disability due to low back pain: an international evidence synthesis. Health Policy. 2017;121(8):903-91.

26. Esser I, Palme J. Do public pensions matter for health and wellbeing among retired persons? Basic and income security pensions across 13 Western European countries. Int J Soc Welf. 2010;19:103-20.

27. Grant G, Studdert DM. Poisoned chalice? A critical analysis of the evidence linking personal injury compensation processes with adverse health outcomes. Melb U L Rev. 2009;33(3):865-85.

28. Weathers RR $2 n d$, Stegman M. The effect of expanding access to health insurance on the health and mortality of social security disability insurance beneficiaries. J Health Econ. 2012;31(6):863-75.

29. Ma X. Public medical insurance system reform and the determinants of participation to the medical insurance systems in the ageing China. J Popul Probl. 2016:72(3):236-55.

30. Meng Q, Fang H, Liu X, Yuan B, Xu J. Consolidating the social health insurance schemes in China: towards an equitable and efficient health system. Lancet. 2015;386(10002):1484-92.

31. Ning M, Gong J, Zheng XH, Zhuang J. Does new rural pension scheme decrease elderly labor supply? Evidence from CHARLS. China Econ Rev. 2016:41:315-30.

32. Luo HQ, Ren XH, Li JJ, Wu K, Wang YX, Chen Q, Li NX. Association between obesity status and successful aging among older people in China: evidence from CHARLS. BMC Public Health. 2020;20(1):502.

33. Ma X, Piao X, Oshio T. Impact of social participation on health among middle-aged and elderly adults: evidence from longitudinal survey data in China. BMC Public Health. 2020;20(1):502.

34. Lu B, Yang MX, Cumming RG, Stanaway FF. Falls and impact on disability and healthy life expectancy in China: evidence from the China health and retirement longitudinal survey (CHARLS). China Econ Rev. 2020.

35. Knight J, Li S, Wan H. The increased trend of wealth inequality in China. In: Li S, Yue $X$, Sicular T, Sato H, editors. The latest change of income distribution in China. Beijing:China Financial Economy Press. 2017. p. 80-118

36. Contoyannis $\mathrm{P}$, Jones $\mathrm{A}$, Rice $\mathrm{N}$. The dynamics of health in the British household panel survey. J Appl Econ. 2004;19(4):473-503.

37. Wooldridge J. Simple solutions to the initial conditions problem in dynamic, nonlinear panel data models with unobserved heterogeneity. J Appl Econ 2005;20(1):39-54

38. Wooldridge J. Econometric analysis of cross section and panel data. Cambridge: The MIT Press; 2020.

39. Rothman KJ, Poole C. Science and policy making. Am J Public Health. 1985; 75:340-1.

40. Green WH. Econometric analysis. 2012. Prentice Hall.

41. Wang H, Yip W, Zhang L, Hsiao WC. The impact of rural mutual health care on health status: evaluation of a social experiment in rural China. Health Econ. 2009:18(Suppl 2):S65-82.

42. Shu $L$. The effects of the new rural social pension insurance program on the retirement and labor supply decision in China. J Econ Ageing. 2018;12:125-50.

\section{Publisher's Note}

Springer Nature remains neutral with regard to jurisdictional claims in published maps and institutional affiliations.

Ready to submit your research? Choose BMC and benefit from:
- fast, convenient online submission
- thorough peer review by experienced researchers in your field
- rapid publication on acceptance
- support for research data, including large and complex data types
- gold Open Access which fosters wider collaboration and increased citations
- maximum visibility for your research: over 100M website views per year
At BMC, research is always in progress.
Learn more biomedcentral.com/submissions

